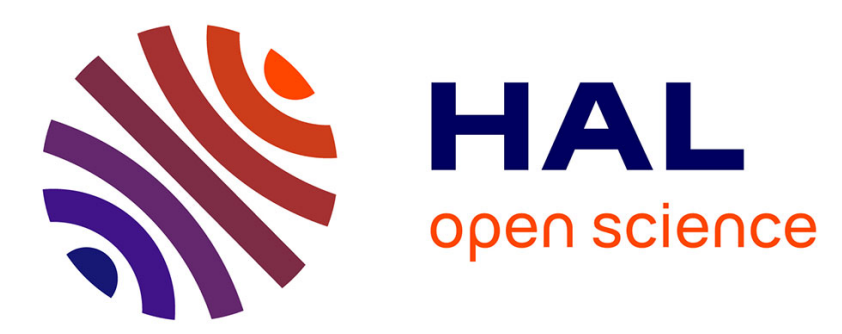

\title{
A robust multivariable control for an electropneumatic system using backstepping design
}

Mohamed Smaoui, Xavier Brun, Daniel Thomasset

\section{To cite this version:}

Mohamed Smaoui, Xavier Brun, Daniel Thomasset. A robust multivariable control for an electropneumatic system using backstepping design. Symposium on Nonlinear Control Systems, NOLCOS 6th IFAC symposium, Sep 2004, Stuttgart, Germany. pp.1193-1198, 10.1016/S1474-6670(17)31342-3 . hal-02066857

\section{HAL Id: hal-02066857 \\ https://hal.science/hal-02066857}

Submitted on 2 Apr 2019

HAL is a multi-disciplinary open access archive for the deposit and dissemination of scientific research documents, whether they are published or not. The documents may come from teaching and research institutions in France or abroad, or from public or private research centers.
L'archive ouverte pluridisciplinaire HAL, est destinée au dépôt et à la diffusion de documents scientifiques de niveau recherche, publiés ou non, émanant des établissements d'enseignement et de recherche français ou étrangers, des laboratoires publics ou privés. 


\title{
A ROBUST MULTIVARIABLE CONTROL FOR AN ELECTROPNEUMATIC SYSTEM USING BACKSTEPPING DESIGN
}

\section{SMAOUI, X. BRUN, D. THOMASSET}

\author{
Laboratoire d'Automatique Industrielle - INSA de Lyon \\ http://www-lai.insa-lyon.fr/ \\ Bât Antoine de SAINT-EXUPERY, 25, avenue Jean Capelle \\ 69621 Villeurbanne Cedex, France \\ Tel: (33) 472438881 Fax: (33) 472438535 \\ Email:mohamed.smaoui@insa-lyon.fr
}

\begin{abstract}
During the last twenty years, the parallel development of pneumatic systems and control theory has lead to the implementation of modern control laws in pneumatic devices. This paper deals with the robust control problem of a pneumatic actuator subjected to mass flow leakage inside the servodistributor and load disturbances. The control strategy is based on backstepping design.

For this, backstepping is presented in an informal setting. The nonlinear model of the electropneumatic system is presented. This one is transformed to be nonlinear affine model and a coordinate transformation is then related to make possible the implementation of the nonlinear controller. Control laws are developed using backstepping design to control position and pressure. The robustness vis-a-vis modeling errors and some unknown terms is proved. Finally, the experiment results are presented and discussed.
\end{abstract}

Keywords: Electropneumatic system, backstepping control, multivariable control, tracking.

\section{NOMENCLATURE}

\begin{tabular}{|c|c|}
\hline$b$ & viscous friction coefficient $(\mathrm{N} / \mathrm{m} / \mathrm{s})$ \\
\hline$k$ & polytropic constant \\
\hline$M$ & total load mass $(\mathrm{kg})$ \\
\hline$p$ & pressure in the cylinder chamber $(\mathrm{Pa})$ \\
\hline$q_{m}$ & $\begin{array}{l}\text { mass flow rate provided from } \\
\text { servodistributor to cylinder chamber } \\
(\mathrm{kg} / \mathrm{s})\end{array}$ \\
\hline$r$ & $\begin{array}{l}\text { perfect gas constant related to unit } \\
\text { mass }(\mathrm{J} / \mathrm{kg} / \mathrm{K})\end{array}$ \\
\hline$S$ & area of the piston cylinder $\left(\mathrm{m}^{2}\right)$ \\
\hline$T$ & temperature $(\mathrm{K})$ \\
\hline$V$ & volume $\left(\mathrm{m}^{3}\right)$ \\
\hline$y, v, a$ & $\begin{array}{l}\text { position }(\mathrm{m}), \quad \text { velocity } \\
\text { acceleration }\left(\mathrm{m} / \mathrm{s}^{2}\right)\end{array}$ \\
\hline$\varphi()$. & leakage polynomial function $(\mathrm{kg} / \mathrm{s})$ \\
\hline$\psi()$. & polynomial function $(\mathrm{kg} / \mathrm{s} / \mathrm{V})$ \\
\hline$l$ & length of stroke (m) \\
\hline \multicolumn{2}{|c|}{ Subscript } \\
\hline ext & external \\
\hline$D$ & dead volume \\
\hline$S$ & supply \\
\hline$N$ & chamber $\mathrm{N}$ \\
\hline$P$ & chamber $\mathrm{P}$ \\
\hline $\mathrm{d}$ & desired \\
\hline
\end{tabular}

\section{INTRODUCTION}

Pneumatic control systems play important roles in industrial automation, due to their relatively small size, light weight and high speed and easy power translation. One of the conspicuous trends is the need for the electropneumatic systems that can achieve precise tracking position control (Edge,1997). For this, modern control theory can be applied to design a suitable controller for pneumatic systems such as feedback linearization (Kimura et al., 1997), fuzzy control (Parnichkun and Ngaecharoenkul, 2001) and sliding mode control (Bouri and Thomasset, 2001; Yang, \& Lilly, 2003).

Backstepping (Kanellakopoulos et al., 1991; Freeman and Kokotović, 1993) control is an approach to nonlinear control design which has attracted a great deal of research interest in recent years. It is mainly applicable to systems having a cascaded or triangular structure. The central idea of the approach is to recursively design controllers for subsystems in the structure and "step back" the feedback signals towards the control input. This differs from the conventional feedback linearization in that it offers a more flexible way of dealing with uncertainties. Using the Lyapunov functions, their impact on the system can be analyzed so that stabilizing and thus in a sense useful, nonlinearities 
may be kept while harmful nonlinearities can be cancelled or dominated by the control signal.

This approach has been used in this paper in the context of an electropneumatic system. The remainder of the paper is organized as follows. Section 2 presents backstepping in an informal setting. In section 3, a nonlinear model describing the electropneumatic system is presented, and in section 4 , the backstepping control law is derived in detail. The experiment results are presented and discussed.in section 5

\section{BACKSTEPPING}

Backstepping is a recursive procedure, which allows deriving control law for a nonlinear system, associated with appropriate Lyapunov function, which guaranties stability.

Classes of systems, for which this procedure works, are given in (Kristic et al., 1995; Alleyne and Liu, 2000; Khalil, 2001). One of such classes is so called strict-feedback system (1).

$$
\left\{\begin{array}{l}
\dot{x}=f_{0}(x)+g_{0}(x) z_{1} \\
\dot{z}_{1}=f_{1}\left(x, z_{1}\right)+g_{1}\left(x, z_{1}\right) z_{2} \\
\dot{z}_{2}=f_{2}\left(x, z_{1}, z_{2}\right)+g_{2}\left(x, z_{1}, z_{2}\right) z_{3} \\
\quad \vdots \\
\dot{z}_{n-1}=f_{n-1}\left(x, z_{1}, z_{2}, \ldots, z_{n-1}\right)+g_{n-1}\left(x, z_{1}, z_{2}, \ldots, z_{n-1}\right) z_{n} \\
\dot{z}_{n}=f_{n}\left(x, z_{1}, z_{2}, \ldots, z_{n}\right)+g_{n}\left(x, z_{1}, z_{2}, \ldots, z_{n}\right) u
\end{array}\right.
$$

where $x \in \mathfrak{R}^{\mathrm{n}}, z_{1}$ to $z_{n}$ are scalars, and $f_{0}$ to $f_{n}$ vanish at the origin. The reason for referring to such systems as "strict feedback" is that the nonlinearities $f_{i}$ and $g_{i}$ in the $\dot{z}_{\mathrm{i}}$-equation $(i=1, \ldots, n-1)$ depend only on $x, z_{1}$, $\ldots, z_{i+1}$; that is, on the state variables that are "feed back".

One assume that :

$g_{i}\left(x, z_{1}, \ldots, z_{i}\right) \neq 0$ for $1 \leq i \leq n$

over the domain of interest. The recursive procedure starts with the system:

$\dot{x}=f_{0}(x)+g_{0}(x) z_{1}$

where $z_{1}$ is viewed as the control input. One assume that it is possible to determine a stabilizing state feedback control law $z_{1}=\alpha_{0}(x)$, with $\alpha_{0}(0)=0$, and a Lyapunov function $V_{0}(x)$ such that

$$
\frac{\partial V_{0}}{\partial x}\left[f_{0}(x)+g_{0}(x) \alpha_{0}(x)\right] \leq-W(x)
$$

over the domain of interest for some positive definite function $W(x)$. In many applications of backstepping, the variable $x$ is scalar, which simplifies this stabilization problem.

However, $z_{1}$ is not available for control. The key property of backstepping is that it offers a constructive way of forwarding the unattainable control $z_{1}=\alpha_{0}(x)$ to a new virtual control law $z_{2}=$ $\alpha_{l}\left(x, z_{l}\right)$. If this could be satisfied, $x$ and $z_{l}$ would be successfully brought back to the origin. This recursive procedure is repeated until the actual control variable $u$ is reached after $n$ steps, whereby a stabilizing control law, $u=\alpha_{n}\left(x, z_{1}, \ldots, z_{n}\right)$, is established.

Along with the control law, a Lyapunov function is constructed, proving the global stability of the closed loop system. Indeed, at the $i$-th step a $V_{i-l}$ Lyapunov function is known, which stabilises $i$ equations. It is associated with a virtual control law $\alpha_{i-1}$. Backstepping has been used either in the cases where the controller is smooth time-varying (Jiang and Nijmeijer, 1998) or within the regions where the discontinuous controller is smooth (Jiang, 2000). A constructive control design for integrator backstepping in nonsmooth systems has also been addressed in (Tanner and Kyriakopoulos, 2003).

\section{ELECTROPNEUMATIC SYSTEM MODELLING}

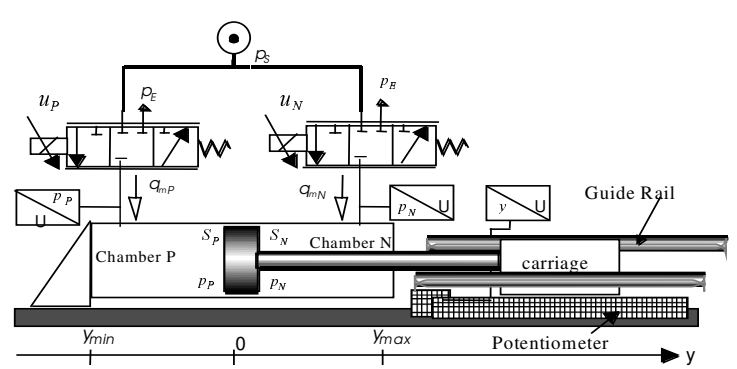

Fig. 1. The electropneumatic system

The electropneumatic system (Fig.1) use the following structure: two three-way proportional servodistributors/ actuator/ mass in translation. The actuator under consideration is an in-line electropneumatic cylinder, using a simple rod (32/20 $\mathrm{mm}$ ) with a stroke equal to $500 \mathrm{~mm}$. The rod is connected to one side of a carriage and drives an inertial load on guiding rails. The total moving mass is equal to $17 \mathrm{~kg}$.

The electropneumatic system model can be obtained using three physical laws: the mass flow rate through a restriction, the pressure behavior in a chamber with variable volume and the fundamental mechanical equation.

In our case, the bandwidth of the Servotronic Joucomatic servodistributor and the actuator are respectively about $200 \mathrm{~Hz}$ and $2,4 \mathrm{~Hz}$. Using the singular perturbation theory, the dynamic of the servodistributors are neglected and his model can be reduced to a static one described by two relationships $q_{m} P\left(u_{P}, p_{P}\right)$ and $q_{m} P\left(u_{N}, p_{N}\right)$ between the mass flow rates $q_{m} P$ and $q_{m} N$, the input voltages $u_{P}$ and $u_{N}$, and the output pressures. Indeed, the servodistributor includes a position sensor supplying a signal proportional to the position of the spool and indicating the flow-rate. The position of the spool is regulated by a PID control law elaborate around a linearized model. The stability of the fast dynamic is guarantied.

The pressure evolution law in a chamber with variable volume is obtained assuming the following assumptions (Shearer, 1956): air is a perfect gas and its kinetic energy is negligible. The pressure and the temperature are supposed to be homogeneous in each chamber. The process is polytropic and characterized by coefficient $k$. Moreover, the electropneumatic system model is obtained by combining all the previous relations and assuming that the temperature variation is negligible with respect to average and equal to the supply temperature. So the following equation gives the model of the above system: 


$$
\left\{\begin{array}{l}
\frac{d y}{d t}=v \\
\frac{d v}{d t}=\frac{1}{M}\left[S_{P} p_{P}-S_{N} p_{N}-b v-F_{e x t}\right] \\
\frac{d p_{P}}{d t}=\frac{k r T}{V_{P}(y)}\left[q_{m}\left(u_{P}, p_{P}\right)-\frac{S_{P}}{r T} p_{P} v\right] \\
\frac{d p_{N}}{d t}=\frac{k r T}{V_{N}(y)}\left[q_{m}\left(u_{N}, p_{N}\right)+\frac{S_{N}}{r T} p_{N} v\right]
\end{array}\right.
$$

Where:

$\left\{\begin{array}{l}V_{P}(y)=V_{P}(0)+S_{P} y \\ V_{N}(y)=V_{N}(0)-S_{N} y\end{array}\right.$

With:

$\left\{\begin{array}{l}V_{p}(0)=V_{D P}+S_{P} \frac{l}{2} \\ V_{N}(0)=V_{D N}+S_{N} \frac{l}{2}\end{array}\right.$

are the piping volumes of the chambers for the zero position and $V_{D(P \text { or } N}$ ) are dead volumes present on each extremities of the cylinder.

The main difficulty for model (5) is to know the mass flow rates $q_{m} p$ and $q_{m}{ }^{N}$. This model is issue of experimental measurement (Sesmat and Scavarda, 1996; Brun et al., 1999) and therefore a mathematical model for a static flow stage has been obtained from a polynomial approximation (Belgharbi et al., 1999) affine in control (equation (6)) and the nonlinear affine model is then given by equation (7)

$$
\begin{aligned}
& q_{m}(u, p)=\varphi(p)+\psi(p, \operatorname{sgn}(u)) \times u \\
& \left\{\begin{array}{l}
\frac{d y}{d t}=v \\
\frac{d v}{d t}=\frac{1}{M}\left[S_{P} p_{P}-S_{N} p_{N}-b v-F_{e x t}\right] \\
\frac{d p_{P}}{d t}=\frac{k r T}{V_{P}(y)}\left[\varphi\left(p_{P}\right)-\frac{S_{P}}{r T} p_{P} v\right]+\frac{k r T}{V_{P}(y)} \psi\left(p_{P}, \operatorname{sgn}\left(u_{P}\right)\right) \times u_{P} \\
\frac{d p_{N}}{d t}=\frac{k r T}{V_{N}(y)}\left[\varphi\left(p_{N}\right)+\frac{S_{N}}{r T} p_{N} v\right]+\frac{k r T}{V_{N}(y)} \psi\left(p_{N}, \operatorname{sgn}\left(u_{N}\right)\right) \times u_{N}
\end{array}\right.
\end{aligned}
$$

With two inputs $u_{P}$ and $u_{N}$, the nonlinear model of the system in Fig. 1 has the following form:

$$
\underline{\dot{x}}=f(\underline{x})+g(\underline{x}) \times \underline{U}
$$

with

$$
x^{T}=\left(y, v, p_{P}, p_{N}\right)
$$

where:

$$
\begin{gathered}
f(\underline{x})=\left(\begin{array}{c}
v \\
\frac{1}{M}\left[S_{P} p_{P}-S_{N} p_{N}-b v-F_{e x t}\right] \\
\frac{k r T}{V_{P}(y)}\left[\varphi\left(p_{P}\right)-\frac{S_{P}}{r T} p_{P} v\right] \\
\frac{k r T}{V_{N}(y)}\left[\varphi\left(p_{N}\right)+\frac{S_{N}}{r T} p_{N} v\right]
\end{array}\right) \\
g(\underline{x})=\left(g_{l}(\underline{x}), g_{2}(\underline{x})\right)=\left(\begin{array}{cc}
\frac{k r T}{V_{P}(y)} \psi\left(p_{P}, \operatorname{sgn}\left(u_{P}\right)\right) & 0 \\
0 & 0 \\
0 & \frac{k r T}{V_{N}(y)} \psi\left(p_{N}, \operatorname{sgn}\left(u_{N}\right)\right)
\end{array}\right) \\
\underline{U}^{T}=\left(u_{P}, u_{N}\right)
\end{gathered}
$$

Using two servo-distributors leads to a system with two degrees of freedom according to the control and this opportunity is exploited to achieve two different control objectives. Taking advantage of the supplementary degree of freedom issued from this new design, it is possible to control another output other than the position control.

Let's define $h(\underline{x})$ the vector constituted of the two chosen outputs: position and pressure in chamber $p$

$$
h(\underline{x})=\left(\begin{array}{l}
h_{l}(\underline{x}) \\
h_{2}(\underline{x})
\end{array}\right)=\left(\begin{array}{l}
y \\
p_{P}
\end{array}\right)
$$

In order to use a backstepping technique, a coordinate transformation is proposed as follows :

$\underline{z}=\phi(\underline{x})=\left[\begin{array}{l}h_{l}(\underline{x})=y \\ L_{f} h_{l}(\underline{x})=v \\ L^{2} h_{l}(\underline{x})=a \\ h_{2}(\underline{x})=p_{P}\end{array}\right]$

$\left\{\begin{array}{l}\frac{d y}{d t}=v \\ \frac{d v}{d t}=a \\ \frac{d a}{d t}=L^{3} h_{l}\left(\phi^{-1}(\underline{z})\right)+L_{g l} L_{f}^{2} h_{l}\left(\phi^{-1}(\underline{z}) u_{p}+L_{g 2} L_{f}^{2} h_{l}\left(\phi^{-1}(\underline{z})\right) u_{N}\right. \\ \frac{d p_{p}}{d t}=L_{f} h_{2}\left(\phi^{-1}(\underline{z})\right)+L_{g l} h_{2}\left(\phi^{-1}(\underline{z})\right) u_{P}\end{array}\right.$

Where:

$$
\begin{aligned}
& L^{3} h_{l}(\underline{x})=\frac{k r T}{M}\left[\frac{S_{p}}{V_{p}(y)} \varphi\left(p_{p}\right)-\frac{S_{N}}{V_{N}(y)} \varphi\left(p_{N}\right)\right. \\
& \left.-\frac{v}{r T}\left(\frac{S_{p}^{2} p_{P}}{V_{P}(y)}+\frac{S_{N}^{2} p_{N}}{V_{N}(y)}\right)\right]-\frac{b}{M^{2}}\left(S_{P} p_{P}-S_{N} p_{N}-b v-F_{e x t}\right) \\
& =\frac{k r T}{M}\left(\frac{S_{p}}{V_{p}(y)} \varphi\left(p_{p}\right)-\frac{S_{N}}{V_{N}(y)} \varphi\left(p_{N}\right)-F_{3}\left(y, p_{P}, p_{N}\right)\right) \\
& -\frac{b}{M^{2}} G\left(v, p_{P}, p_{N}\right) \\
& L_{g l} L_{f}{ }^{2} h_{l}(\underline{x})=\frac{k r T S_{p}}{M V_{P}(y)} \psi\left(p_{P}, s g n\left(u_{P}\right)\right) \\
& L_{g 2} L_{f}{ }^{2} h_{l}(\underline{x})=-\frac{k r T S_{N}}{M V_{N}(y)} \psi\left(p_{N}, s g n\left(u_{N}\right)\right) \\
& =\frac{H\left(y, p_{N}, u_{N}\right)}{M} \\
& L_{f} h_{2}(\underline{x})=\frac{k r T}{V_{P}(y)}\left[\varphi\left(p_{P}\right)-\frac{S_{P}}{r T} p_{P} v\right] \\
& L_{g l} h_{2}(\underline{x})=\frac{k r T}{V_{P}(y)} \psi\left(p_{P}, s g n\left(u_{P}\right)\right)
\end{aligned}
$$

Using the electropneumatic model (11), the control laws are synthesized in the next section using backstepping technique. It is important to note that, in literature, backstepping is applied for SISO systems. The novelty of this paper concerns the implementation of this strategy for a MIMO system.

\section{CONTROL SYNTHESIS}

In this paper, backstepping is applied for a MIMO system (Outputs: $y$ and $p_{P}$, Inputs: $u_{P}$ and $u_{N}$ ).

The aim of the control law is to respect a good accuracy in term of position and pressure tracking. 
As is shown in (Brun et al., 2002), this strategy allows to a minimum energy consumption. Indeed, to reduce the consumed energy, it is possible to decrease the mass flow rate delivered by each servodistibutor.

To reduce the mass flow rate, two aspects are very important:

- the values of the control signal must be small

- the pressure variation must be small

So the choice is about elaborating a desired pressure trajectory in chamber P: This solution is easy to implement and does not need an additional sensor.

Moreover, a second important argument that led us to choose the pressure as the second output is its property of flatness (Fliess et al., 1995). Indeed, position and pressure are flat outputs, the characteristic number associated to the pressure $p$ and the position are, respectively, one and three.

Thus, the sum is equal to the dimension of the system. This is sufficient to affirm that the system is differentially flat.

It is supposed that two kinds of uncertainties are presented on this system.:

*The mass flow leakage inside the servodistributor $(\varphi()$.

*During the load moving and for different object to transport the total mass in displacement can evolve from $M_{\min }$ until $M_{\max }$

One can note that :

- $\varphi$ (.) is limited over the physical domain as the pressures are limited by the exhaust pressure (1 bar) and the supply pressure ( 7 bar) (see Fig. 2).

$-\psi() \neq$.0 over the physical domain (see Fig.3)

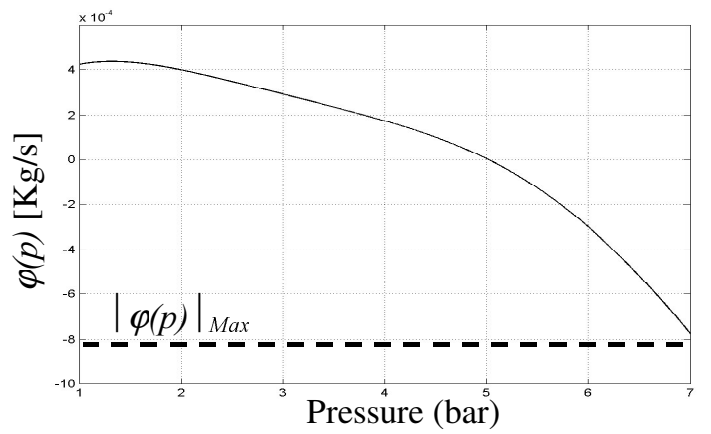

Fig.2. The function $\varphi\left(p_{P}\right)$

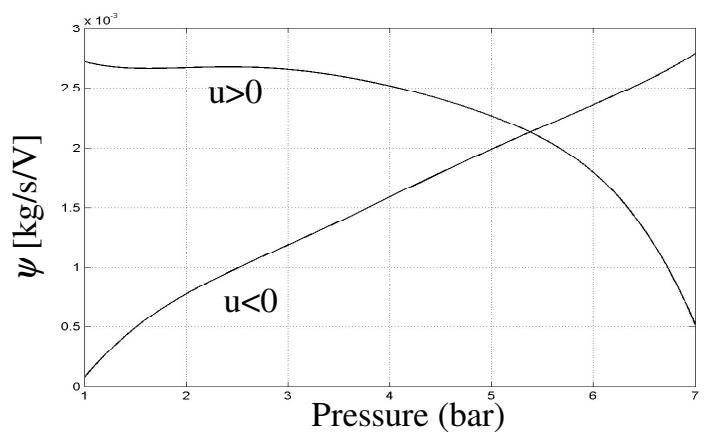

Fig. 3. The function $\psi(P, \operatorname{sgn}(u))$

Firstly, in order to track a desired pressure $p_{P}^{d}, \mathrm{a}$ pressure error is defined as follows:

$$
\begin{aligned}
& e_{4}=p_{P}-p_{P}^{d} \\
& \frac{d e_{4}}{d t}=L_{f} h_{2}\left(\phi^{-1}(\underline{z})\right)+L_{g l} h_{2}\left(\phi^{-1}(\underline{z})\right) u_{P}-\dot{p}_{p}^{d}
\end{aligned}
$$

It is clear that the derivative of the pressure error depends only one input $\left(u_{P}\right)$, this is why, this subsystem (equation (18)) is firstly selected.

Taking $V\left(e_{4}\right)=\frac{1}{2} e_{4}^{2}$ as a Lyapunov function, then the derivative of this function is as

$\dot{V}\left(e_{4}\right)=e_{4}\left[\frac{k r T}{V_{P}(y)}\left(\varphi\left(p_{P}\right)-\frac{S_{P}}{r T} p_{P} v\right)+\frac{k r T}{V_{P}(y)} \psi\left(p_{P}, \operatorname{sgn}\left(u_{P}\right)\right) u_{P}-\dot{p}_{p}^{d}\right]$

$u_{p}$ is chosen as:

$$
\begin{aligned}
& u_{p}=\frac{1}{L_{g l} h_{2}\left(\phi^{-1}(\underline{z})\right)}\left[-\frac{k r T}{V_{P}(y)}\left[\left|\varphi\left(p_{P}\right)\right|_{\operatorname{Max}} \operatorname{sgn}\left(e_{4}\right)-\frac{S_{P}}{r T} p_{P} v\right]\right. \\
& \left.+\dot{p}_{p}^{d}-c_{4} e_{4}\right]=\frac{K\left(y, v, p_{p}, p_{p}^{d}, \dot{p}_{p}^{d}\right)}{L_{g l} h_{2}\left(\phi^{-1}(\underline{z})\right)}
\end{aligned}
$$

So the derivative of the Lyapunov function becomes:

$$
\begin{aligned}
& \dot{V}\left(e_{4}\right)=-c_{4} e_{4}^{2}-\frac{k r T}{V_{P}(y)}\left|\varphi\left(p_{P}\right)\right|_{M a x}\left|e_{4}\right| \\
& +\frac{k r T}{V_{P}(y)} \varphi\left(p_{P}\right) e_{4}<-c_{4} e_{4}^{2}<0
\end{aligned}
$$

The control law (equation (20)) allows to ensure the negativity of the derivative of the lyapunov function in spite of the uncertainties presented in the mass flow leakage inside the servodistributor.

Once the control law $u_{P}$ is found, the objective is to find the second control law $u_{N}$ in order to track a desired position. For this, a postion error is defined as follows:

$$
\begin{aligned}
& e_{1}=y-y_{d} \\
& \dot{e}_{1}=v-v_{d}
\end{aligned}
$$

with $v$ viewed as the input, the feedback control $v=$ $\alpha\left(e_{1}\right)$ is designed to stabilize the origin $e_{1}=0$ with:

$$
v=-c_{1} e_{1}+v_{d}=\alpha_{1}\left(e_{1}, v_{d}\right)
$$

$\dot{e}_{1}=-c_{1} e_{1}$

and $V\left(e_{1}\right)=\frac{1}{2} e_{1}^{2}$ satisfies:

$\dot{V}\left(e_{1}\right)=-c_{1} e_{1}^{2}<0$

a velocity error is defined as follow:

$e_{2}=v-\alpha_{1}\left(e_{1}, v_{d}\right)=v-v_{d}+c_{1} e_{1}$

the $(y, v)$-subsystem is transformed into the form:

$\left\{\begin{array}{l}\dot{e}_{1}=e_{2}-c_{1} e_{1} \\ \dot{e}_{2}=a-a_{d}+c_{1}\left(e_{2}-c_{1} e_{1}\right)\end{array}\right.$

Taking $V\left(e_{1}, e_{2}\right)=\frac{1}{2} e_{1}^{2}+\frac{1}{2} e_{2}^{2}$ as a composite Lyapunov function. The derivative of $V\left(e_{1}, e_{2}\right)$ is computed as:

$\dot{V}\left(e_{1}, e_{2}\right)=-c_{1} e_{1}^{2}+e_{2}\left(e_{1}+a-a_{d}+c_{1}\left(e_{2}-c_{1} e_{1}\right)\right)$

Taking:

$a=-e_{1}+a_{d}-c_{1}\left(e_{2}-c_{1} e_{1}\right)-c_{2} e_{2}=\alpha_{2}\left(e_{1}, e_{2}, a_{d}\right)$

This ensures the negativity of derivative of the Lyapunov function.

$\dot{V}\left(e_{1}, e_{2}\right)=\dot{V}\left(e_{1}\right)-c_{2} e_{2}^{2}=-c_{1} e_{1}^{2}-c_{2} e_{2}^{2}<0$

for some $c_{2}\left[s^{-1}\right]>0$.

An acceleration error is defined as follow:

$e_{3}=a-\alpha_{2}\left(e_{1}, e_{2}, a_{d}\right)$

The $(y, v, a)$-subsystem is transformed into the form: 


$$
\left\{\begin{array}{l}
\dot{e}_{1}=e_{2}-c_{1} e_{1} \\
\dot{e}_{2}=e_{3}-z_{l}-c_{2} e_{2} \\
\dot{e}_{3}=L^{3}{ }_{f} h_{l}\left(\phi^{-1}(\underline{z})\right)+L_{g l} L_{f}{ }^{2} h_{l}\left(\phi^{-1}(\underline{z})\right) u_{p} \\
+L_{g 2} L_{f}{ }^{2} h_{l}\left(\phi^{-1}(\underline{z})\right) u_{N}-j_{d}+\left(c_{1}+c_{2}\right) \\
\left(e_{3}-e_{1}-c_{2} e_{2}\right)+\left(1-c_{1}^{2}\right)\left(e_{2}-c_{1} e_{1}\right)
\end{array}\right.
$$

Using $V\left(e_{1}, e_{2}, e_{3}\right)=\frac{1}{2} e_{1}^{2}+\frac{1}{2} e_{2}^{2}+\frac{1}{2} M e_{3}^{2} \quad$ as a composite Lyapunov function, then the derivative of this function is as

$$
\begin{aligned}
& \dot{V}\left(e_{1}, e_{2}, e_{3}\right)=-c_{1} e_{1}^{2}-c_{2} e_{2}^{2}+e_{3}\left[e_{2}+k r T s\left(\frac{S_{p}}{V_{p}(y)} \varphi\left(p_{p}\right)\right.\right. \\
& \left.-\frac{S_{N}}{V_{N}(y)} \varphi\left(p_{N}\right)-F_{3}\left(y, p_{P}, p_{N}\right)\right)-\frac{b}{M} G\left(v, p_{P}, p_{N}\right) \\
& \left.+S_{p} K\left(y, v, p_{p}, p_{p}^{d}, \dot{p}_{p}^{d}\right)+H\left(y, p_{N}, u_{N}\right) u_{N}+M I\left(e_{1}, e_{2}, e_{3}\right)\right]
\end{aligned}
$$

where

$$
\begin{aligned}
& I\left(e_{1}, e_{2}, e_{3}\right)=-j_{d}+\left(c_{1}+c_{2}\right)\left(e_{3}-e_{1}-c_{2} e_{2}\right) \\
& +\left(1-c_{1}^{2}\right)\left(e_{2}-c_{1} e_{1}\right)
\end{aligned}
$$

In order to ensure the negativity of the derivative of the Lyapunov function in spite of mass flow leakage inside the servodistributor and load disturbances, $u_{N}$ is chosen as:

$u_{N}=\frac{1}{H\left(\left(y, p_{N}, u_{N}\right)\right.}\left[-e_{2}-k r T \frac{S_{p}}{V_{p}(y)}\left|\varphi\left(p_{p}\right)\right|_{\max } \operatorname{sgn}\left(e_{3}\right)\right.$

$-k r T_{s} \frac{S_{N}}{V_{N}(y)}\left|\varphi\left(p_{N}\right)\right|_{\max } \operatorname{sgn}\left(e_{3}\right)+k r T F_{3}\left(y, p_{P}, p_{N}\right)$

$-\frac{b}{M_{\min }} G\left(v, p_{P}, p_{N}\right) \operatorname{sgn}\left(G\left(v, p_{P}, p_{N}\right) e_{3}\right)$

$-S_{p} K\left(y, v, p_{p}, p_{p}^{d}, \dot{p}_{p}^{d}\right)-M_{\max } I\left(e_{1}, e_{2}, e_{3}\right) \operatorname{sgn}\left(I\left(e_{1}, e_{2}, e_{3}\right) e_{3}\right)$

$-c_{3} e_{3}$

The derivative of the Lyapunov function becomes:

$\dot{V}\left(z_{1}, z_{2}, z_{3}\right)=-c_{1} e_{1}^{2}-c_{2} e_{2}^{2}-c_{3} e_{3}^{2}-\frac{b}{M} G\left(v, p_{P}, p_{N}\right) e_{3}$

$-\frac{b}{M_{\min }}\left|G\left(v, p_{P}, p_{N}\right) e_{3}\right|+M I\left(e_{1}, e_{2}, e_{3}\right) e_{3}$

$-M_{\max }\left|I\left(e_{1}, e_{2}, e_{3}\right) e_{3}\right|+K r T\left\{\frac{S_{p}}{V_{p}(y)}\left[\varphi\left(p_{p}\right) e_{3}\right.\right.$

$\left.\left.-\left|\varphi\left(p_{p}\right)\right|_{\max }\left|e_{3}\right|\right]-\frac{S_{N}}{V_{N}(y)}\left[\varphi\left(p_{N}\right) e_{3}+\left|\varphi\left(p_{N}\right)\right|_{\max }\left|e_{3}\right|\right]\right\}$

$\leq-c_{1} e_{1}^{2}-c_{2} e_{2}^{2}-c_{3} e_{3}^{2}<0$

Given the system described in (7), the actual inputs defined in (20) and (36) are applied to the electropneumatic system.

\section{EXPERIMENT RESULTS}

The relative order of the position output of the electropneumatic system is three. This means that there are "three integrators" between the control input of the system and the output, which is the cylinder piston position. This means that the electropneumatic system can only track position trajectories at least three times differentiable. The desired trajectories are been carefully chosen in order to respect the differentiability required. The desired pressure is variable when the load is moving and is then differentiable.

This controller was implemented using a dSpace DS1104 controller board with a dedicated digital signal processor. The sensed signals, all analog, were run through the signal conditioning unit before being read by the A/D converter.

The velocity cylinder is determined by analog differentiating and low-pass filtering the output of the position. The acceleration information is obtained by differentiating numerically the velocity.

Some experiment results are provided here to demonstrate the robustness of the backstepping controller.

Firstly, the total load mass is $17 \mathrm{~kg}$.

Fig. 4 show the position, the desired position, the position error, the pressure in chamber $p$, the desired pressure in chambers $p$ and the pressure error.

From the experiments results, a good tracking responses are obtained for the position and pressure in chamber $p$ owing to the robust control characteristics of the backstepping controller.
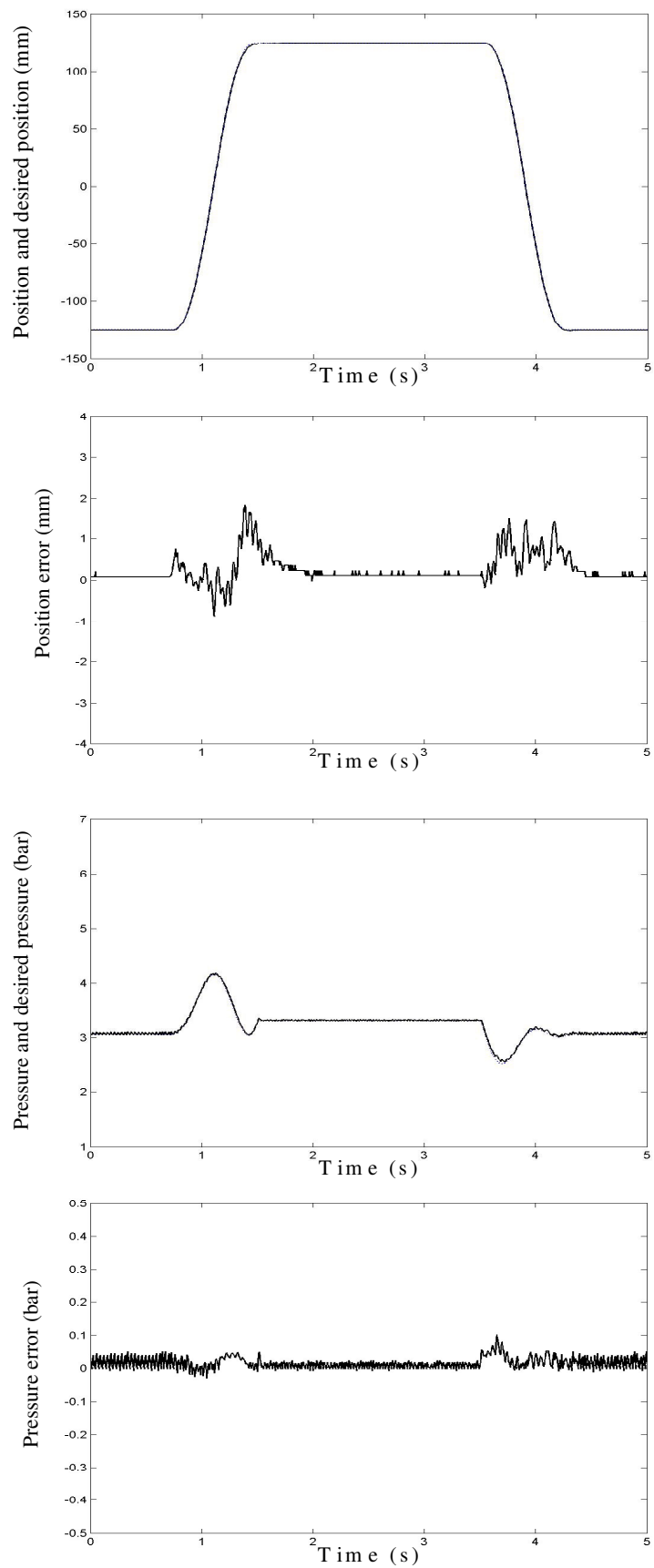

Fig 4. Experiment results of backstepping controller $\mathrm{M}=17 \mathrm{~kg}$.

To check the robustness of the backstepping controller via load disturbance, experiment results are reproduced in Fig. 5 without changing the control 
gains values and when the total load mass is equal to $32 \mathrm{~kg}$.

The robust control characteristics of backstepping controller can be observed.

The maximum position tracking error is about 0.875 $m m$ at $t=3.88 \mathrm{~s}$ and the maximum pressure tracking error is about 0.056 bar at the same time. In steady state, the position error is about $79 \mu \mathrm{m}$ when the desired position is $-125 \mathrm{~mm}$ and $106 \mu \mathrm{m}$ when the desired position is $125 \mathrm{~mm}$.

A multivariable control law based on the flatness theory is developed in (Brun et al., 2002). The maximum position error is about $5,35 \mathrm{~mm}$. In steady state, the position error is near to $0.5 \mathrm{~mm}$. So, the tracking performance obtained by the backstepping algorithm is good in regard of precedents one.
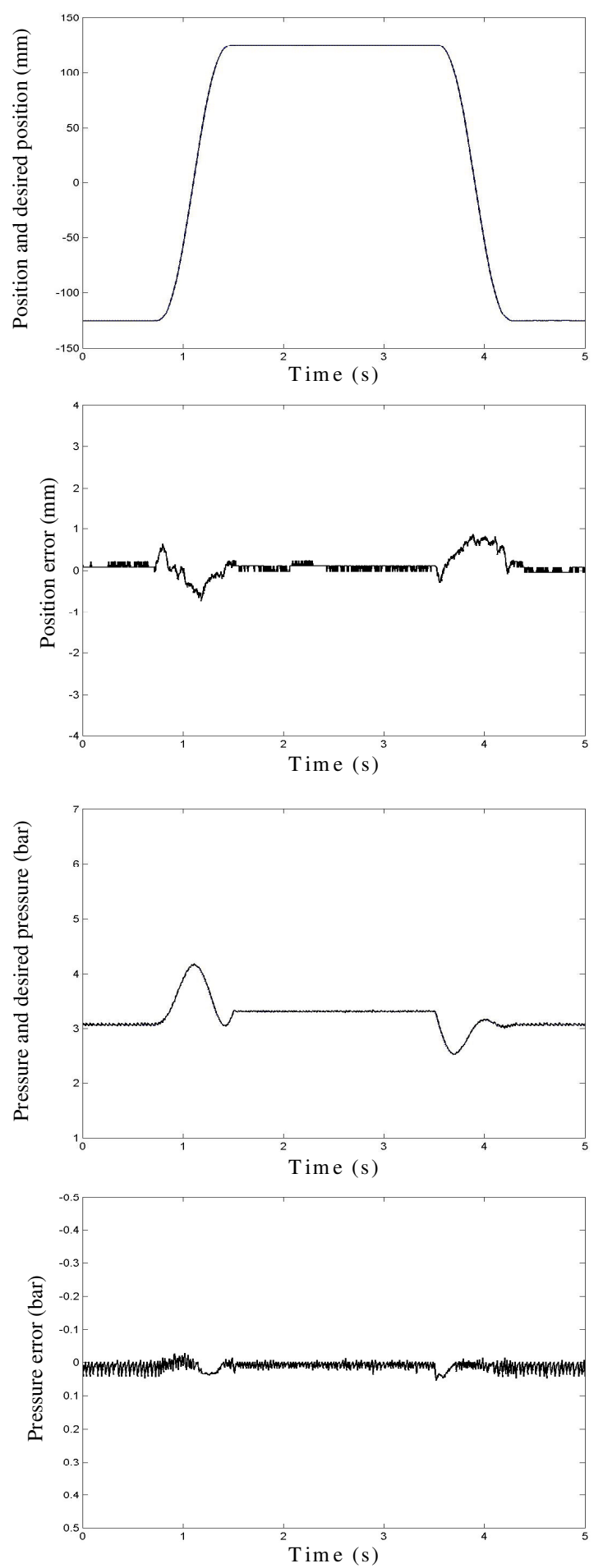

Fig 5. Experiment results of backstepping controller $\mathrm{M}=32 \mathrm{~kg}$.

\section{CONCLUSION}

This paper has successfully demonstrated the application of a MIMO backstepping controller to control the position and the pressure (in one chamber) of an electropneumatic system. Firstly, the mathematical model of the electropneumatic system was introduced. Then, the theoretical bases of the controllers were described in detail. The robustness vis-a-vis modeling errors (leakage polynomial function) and unknown terms (total load mass) has been proved. Then, experimentation was carried out to check the effectiveness of the proposed controllers. The obtained experimental results are satisfactory and are in concordance with the numerical results, the required performance are achieved.

Another important aspect of this strategy concerns energy consumption. As noted in section 4, the choice of the pressure in one chamber as a second output allows to reduce the consumed energy.

\section{REFERENCES}

Alleyne, A.and Liu, R. (2000). Systematic Control of a Class of Nonlinear Systems with Application to Electrohydraulic Cylinder Pressure Control. IEEE Transactions on Control Systems Technologies, Vol. 8 No.4, pp. 623-634.

Belgharbi, M., Thomasset, D., Scavarda, S. and Sesmat, S. (1999). Analytical model of the flow stage of a pneumatic Servodistributor for simulation and nonlinear control. In the Sixth Scandinavian International Conference on Fluid. Power, SICFP'99, Tampere, Finland, pp. 847-860

Bouri, M. and Thomasset, D. (2001). Sliding Control of an Electropneumatic Actuator Using an Integral switching Surface. IEEE Transaction on control systems technology. Vol. $9 \mathrm{~N}^{\circ} 2$, pp.368375.

Brun, X., Sesmat, S., Thomasset, D. and Scavarda, S. (1999). A comparative study between two control laws of an electropneumatic actuator. European Control Conference ECC'99 Karlsruhe, [CD Rom], reference F1000-5.

Brun, X., Thomasset, D. and Bideaux, E. (2002). Influence of the process design on the control strategy: application in electropneumatic Field. Control Engineering Practice pp.727-735.

Edge, K.A. (1997). The control of fluid power systems - responding to the challenge. Journal of Systems and Control Engineering, Vol. 211, $\mathrm{N}^{\circ} 12$, pp. 91-110.

Fliess, M., Levine, J., Martin, P.and Rouchon, P. (1995). Flatness and defect of non-linear systems:Introduc tory, theory and applications. International Journal of Control, 61, 1327-1361.

Freeman, R.A.and Kokotović, P. (1993). Design of 'softer' robust nonlinear control laws. Automatica, pp. 1425-1437.

Jiang, Z. -P., and Nijmeijer, H. (1998). Tracking control of mobile robots: A case study in backstepping. Automatica, Vol. 33, No 7, 13931399. 
Jiang, Z. P. (2000). Robust exponential regulation of nonholonomic systems with uncertainties. Automatica, Vol. 36, 189-209.

Kanellakopoulos, I., Kokotović, P. and Morse, A.S. (1991). Systematic design of adaptive controllers for feedback linearizable systems. IEEE Transactions on Automatic Control, Vol. 36, pp. 1241-1253.

Khalil, H. (2001). Nonlinear Systems. Prentice-Hall, third edition, $750 \mathrm{p}$.

Kimura, T., Hara, S., Fujita, T. and Kagawa, T. (1997). Feedback linearization for pneumatic actuator systems with static fiction. Control engineering practice Vol. 5 No 100 pp. 13851394.

Kristic, M., I., Kanellakopoulos and Kokotovic. P.V., (1995). Nonlinear and Adaptive Control Design. John Wiley \& Sons, 563 p.

Parnichkun, M. and Ngaecharoenkul, C., (2001) Kinematics control of a pneumatic system by hybrid fuzzy PID. Mechatronics Vol. 11, pp. 1001-1023.

Sesmat, S. and Scavarda, S. (1996). Static characteristics of a three way servovalve. In: $12^{\text {th }}$ Aachen Conference on Fluid Power Technology, Aachen, Germany, March 12-13, pp. 643-652.

Shearer, J.L. (1956). Study of pneumatic processes in the continuous control of motion with compressed air. Parts I and II. Trans. Am. Soc. Mech. Eng., Vol. 78, pp. 233-249.

Tanner, H.G, Kyriakopoulos, K.J (2003). Backstepping for nonsmooth systems. Automatica, Vol. 39, pp. 1259-1265.

Yang, L. and Lilly, J.H., (2003) Sliding mode tracking for pneumatic muscle actuators in bicep/tricep pair configuration.. Proc. American Control Conference ACC'03, Denver, Colorado, pp.4669-4672. 